\section{Additional Evaluations of Cucumis melo L. Germplasm for Resistance to Downy Mildew}

\author{
C.E. Thomas ${ }^{1}$ \\ U.S. Department of Agriculture, Agricultural Research Service, U.S. Vegetable \\ Laboratory, 2875 Savannah Highway, Charleston, SC 29414
}

Additional index words. melon, Pseudoperonospora cubensis, disease resistance, foliar disease

Abstract. Field evaluations for resistance against downy mildew, incited by Pseudoperonospora cubensis (Berk. \& M.A. Curtis) Rostovzev were conducted on 1076 U.S. Plant Introductions (PI) of Cucumis melo L. (melon). A disease index (DI) was calculated for each entry that had one or more resistant plants. Based on DI, PIs 271329 and 401644 were the most resistant overall (DI $=\mathbf{2 . 6}$ and 2.8, respectively). However, resistant plants exhibiting reaction type (RT) 3 were identified in 68 accessions, and 110 accessions had moderately resistant (RT 2) plants.

Downy mildew of melon and other cucurbits is incited by Pseudoperonospora cubensis. The disease has a wide geographic distribution (Palti, 1975) and causes severe losses in melon production near the Atlantic Seaboard and Gulf of Mexico in the United States (Whitaker and Davis, 1962). The principal methods of disease control are the use of protective fungicides and host resistance (Chupp and Sherf, 1960). Environmental, economic, and energy conservation concerns are placing increasing emphasis on a greater need for development of commercially acceptable, resistant cultivars (Thomas, 1982). The U.S. Plant Introduction collection is a possible source of resistant germplasm against this disease.

The purpose of this study was to evaluate available $C$. melo Plant Introductions (PIs) from the U.S. Plant Introduction (USPI) collection for resistance to a local isolate of $P$. cubensis pathotype 4 , the incitant of downy mildew. Because pathotypes 1, 2,3, 4, and 5 of $P$. cubensis are highly compatible with at least one $C$. melo differential genotype and pathotype 4 is highly compatible with all differential genotypes (Thomas et al., 1987b), evaluations against pathotype 4 should provide a valid indication of potential resistance against it and the other four pathotypes. This report presents the results of the evaluation of $1076 \mathrm{C}$. melo PIs and four control cultivars. It is the second

Received for publication 18 Feb. 1998. Accepted for publication $12 \mathrm{Feb} .1999$. Mention of a trade name or a proprietary product does not constitute a guarantee or warranty of the product by the U.S. Dept. of Agriculture, and does not imply approval of it to the exclusion of other products that also may be suitable. The author gratefully acknowledges the able technical assistance of Horticulturist E.J. Caniglia in the conduct of these studies. The cost of publishing this paper was defrayed in part by the payment of page charges. Under postal regulations, this paper therefore must be hereby marked advertisement solely to indicate this fact.

${ }^{1}$ Research Plant Pathologist. report on the continuing work of evaluating the $C$. melo USPI germplasm collection to identify accessions with resistance to downy mildew (Thomas and Jourdain, 1992).

\section{Materials and Methods}

Preliminary field studies were made in nonreplicated plots to evaluate PI accessions for plants resistant to downy mildew. Plots were composed of two to five plants, depending on availability and viability of seeds. Inoculum was prepared from a local isolate of $P$. cubensis maintained on cotyledons of melon cultivar Ananas Yokneam. Cotyledons that supported abundant sporulation by the pathogen were collected and shaken vigorously in distilled water to dislodge the sporangia. The resulting sporangial suspension was filtered through a layer of cheesecloth, and the concentration was determined with the aid of a hemacytometer and adjusted to $2.0 \times 10^{4}$ sporangia/mL. The adaxial leaf surfaces were sprayed with this inoculum, using a Micro Ulva (Micron Sprayers Ltd., Bromyard, U.K.), when the plants were at the 10-leaf stage. Two and sometimes three inoculations were necessary to ensure adequate disease development if dewfall did not occur following inoculation. In all cases, inocula were prepared and administered as described above. Nineteen days after inoculation, infected leaves of each plant in the plot were visually examined for their downy mildew reaction type (RT) (Thomas et al., 1987a) and the most resistant RT observed for each PI was recorded. Downy mildew RTs were classified on a 1-4 scale of increasing plant resistance where: RT $1=$ susceptible, with irregular, chlorotic lesions 10 to $15 \mathrm{~mm}$ in diameter, with abundant sporulation that may extend beyond the apparent margins of the lesions; RT 2 = moderately resistant, with type " 1 " lesions, described above, mixed with type " 3 " lesions, described below; RT 3 = resistant, with irregular to circular, chlorotic lesions 3 to $4 \mathrm{~mm}$ in diameter, with water-soaked margins beneath and sparse sporulation; RT 4 = highly resistant, with circular, chlorotic lesions $1 \mathrm{~mm}$ in diameter, with necrotic centers and watersoaked margins beneath and extremely limited or no readily apparent sporulation.

Remnant seed of those PIs in which one or more plants had a RT $\geq 2$ in the field trials were used to produce plants for retesting under glasshouse/dew chamber conditions in replicated trials. Twenty-four seeds of each PI were sown in Jiffy Mix (Jiffy Products, Batavia, Ill.) in two No. 812 Com-Packs trays (T.P. Plastics, Minneapolis). The 12 cells of each of the Com-Packs trays were cut in half to produce two sets of six plants each, for a total of four replicates, each with six plants, per entry. These packs of six plants were randomized to form the four replicates. Analysis of variance by randomized complete-block design was performed on the data from all genotypes tested in these replicated trials. Blocks were considered a random effect and genotypes a fixed effect with a random block $\times$ genotype interaction used for testing.

Seedlings were grown in a glasshouse to the two-expanded leaf stage. Inoculum was produced as described above for the field tests, with the exception that the concentration was adjusted to $5.0 \times 10^{3}$ sporangia $/ \mathrm{mL}$. The adaxial surfaces of all leaves of all test and control plants were sprayed with this inoculum to incipient runoff using a Paasche Type $\mathrm{H}$ airbrush (Paasche Airbrush, Chicago) at 275 $\mathrm{kPa}$. After inoculation, plants were placed in a dark $20^{\circ} \mathrm{C}$ dew chamber for $18 \mathrm{~h}$, then kept on a glasshouse bench for $5 \mathrm{~d}$. Six days postinoculation, plants were returned to the dew chamber for $18 \mathrm{~h}$ to enhance sporulation. Classifications for RT were made on the seventh day postinoculation.

Leaves one and two of each plant were observed with the aid of a stereo microscope at magnifications up to $60 \times$ to determine the RT of each plant. These RT ratings were used to calculate a weighted disease index (DI) for each entry using Williams' (1985) formula:

$$
\mathrm{DI}=\frac{\Sigma(\mathrm{i} \times \mathrm{j})}{\mathrm{n}}
$$

where $\mathrm{n}=$ total plants, $\mathrm{i}=$ reaction type, and $\mathrm{j}=$ number plants/reaction type.

\section{Results and Discussion}

In the replicated glasshouse trials, $178 \mathrm{PIs}$ had one or more plants that exhibited at least moderate resistance $(\mathrm{RT} \geq 2)$. Resistant plants $(\mathrm{RT}=3)$ were identified in 68 accessions listed in Table 1. Based on DIs for the 178 accessions with at least moderate resistance, PIs 271329 and 401644 were the most resistant overall, i.e., contained the highest number of plants that were moderately resistant or better [(DI = 2.6 and 2.8 , respectively), LSD $(P=0.05)=$ $\pm 0.4]$, with $96 \%$ and $93 \%$ of the plants having a RT $\geq 2$. The remaining 110 accessions contained only moderately resistant plants $(\mathrm{RT}=$ 2). No PI had a DI as high as that of the highly resistant control, breeding line MR-1 (DI = 4.0), which was derived from 90319 , an inbred line of PI 124111 (Thomas, 1986). However, 
Table 1. Disease indices of melon U.S. Plant Introductions (PI) that had one or more plants with a resistant reaction type $\mathrm{e}^{\mathrm{z}}$ (RT) 3 and melon cultivars to artificial inoculation with Pseudoperonospora cubensis in glasshouse/dew chamber replicated trials.

\begin{tabular}{|c|c|c|c|c|c|c|c|}
\hline $\mathrm{PI} / \mathrm{cv}$. & $\begin{array}{c}\text { Disease } \\
\text { index }^{y}\end{array}$ & $\mathrm{PI} / \mathrm{cv}$. & $\begin{array}{c}\text { Disease } \\
\text { index }\end{array}$ & $\mathrm{PI} / \mathrm{cv}$. & $\begin{array}{c}\text { Disease } \\
\text { index }\end{array}$ & $\mathrm{PI} / \mathrm{cv}$. & $\begin{array}{c}\text { Disease } \\
\text { index }\end{array}$ \\
\hline$\overline{\text { PI } 401644}$ & 2.8 & PI 321005 & 2.0 & PI 482422 & 1.7 & PI 401668 & 1.4 \\
\hline PI 271329 & 2.6 & PI 315409 & 2.0 & PI 482413 & 1.7 & PI 275634 & 1.4 \\
\hline PI 401643 & 2.5 & PI 217974 & 2.0 & PI 381775 & 1.7 & PI 182955 & 1.4 \\
\hline PI 304747 & 2.3 & PI 164609 & 2.0 & PI 288331 & 1.7 & PI 140694 & 1.4 \\
\hline PI 266931 & 2.3 & PI 164328 & 2.0 & PI 179906 & 1.7 & PI 512535 & 1.3 \\
\hline PI 126006 & 2.2 & PI 125976 & 1.9 & PI 179679 & 1.7 & PI 482433 & 1.3 \\
\hline PI 482407 & 2.2 & PI 512551 & 1.9 & PI 401614 & 1.6 & PI 482427 & 1.3 \\
\hline PI 442177 & 2.2 & PI 505600 & 1.9 & PI 378064 & 1.6 & PI 200813 & 1.3 \\
\hline PI 401661 & 2.2 & PI 482431 & 1.9 & PI 378063 & 1.6 & PI 126101 & 1.3 \\
\hline PI 323316 & 2.2 & PI 512423 & 1.8 & PI 183053 & 1.6 & PI 223772 & 1.2 \\
\hline PI 277283 & 2.2 & PI 482421 & 1.8 & PI 500362 & 1.5 & PI 169327 & 1.2 \\
\hline PI 274954 & 2.2 & PI 438685 & 1.8 & PI 489689 & 1.5 & Controls & \\
\hline PI 511890 & 2.1 & PI 420147 & 1.8 & PI 482414 & 1.5 & $\overline{\mathrm{MR}-1}$ & 4.0 \\
\hline PI 505601 & 2.1 & PI 313969 & 1.8 & PI 260651 & 1.5 & Seminole & 2.9 \\
\hline PI 408978 & 2.1 & PI 295341 & 1.8 & PI 136183 & 1.5 & Cinco & 2.0 \\
\hline PI 296345 & 2.1 & PI 271335 & 1.8 & PI 537092 & 1.4 & Ananas & \\
\hline PI 532841 & 2.0 & PI 180713 & 1.8 & PI 482408 & 1.4 & Yokneam & 1.0 \\
\hline PI 426628 & 2.0 & PI 149169 & 1.8 & PI 470252 & 1.4 & & \\
\hline PI 420178 & 2.0 & PI 512466 & 1.7 & PI 441988 & 1.4 & & \\
\hline
\end{tabular}

${ }^{2}$ Leaves one and two on glasshouse-produced plants at the two-expanded leaf stage were inoculated with 5.0 $\times 10^{3}$ sporangia/mL from a local isolate of $P$. cubensis. Inoculated plants were incubated in a dew chamber for $18 \mathrm{~h}$ at $20^{\circ} \mathrm{C}$ and then placed in the glasshouse for $5 \mathrm{~d}$. On the sixth day after inoculation, plants were returned to the $20^{\circ} \mathrm{C}$ dew chamber for $18 \mathrm{~h}$ and ratings for downy mildew reaction type (RT) were made 7 d postinoculation. Reaction type descriptors are as follows: RT 1 =10- to 15-mm irregular, chlorotic lesions with abundant sporulation that may extend beyond the apparent margins of the lesions; RT $2=$ Type " 1 " lesions, above, mixed with type "3" lesions, below; RT 3 =3- to 4-mm irregular to circular chlorotic lesions with water-soaked margins beneath and sparse sporulation; RT $4=1-\mathrm{mm}$, circular, chlorotic lesions with necrotic centers and water-soaked margins beneath and extremely limited or no readily apparent sporulation. ${ }^{\mathrm{y}}$ Weighted disease indices calculated from the RTs observed for each entry. the identification of resistant plants within the PIs tested (Table 1) offers additional sources for the development of downy mildew resistant melon cultivars. Data for all PIs tested were submitted to the U.S. Dept. of Agriculture, Germplasm Resources Information Network (GRIN), for entry into the GRIN database.

\section{Literature Cited}

Chupp, C. and A.F. Sherf. 1960. Vegetable diseases and their control. Ronald Press, New York.

Palti, J. 1975. Pseudoperonospora cubensis. CMI descriptions of pathogenic fungi and bacteria. No. 457, Commonwealth Mycol. Inst., Kew, U.K.

Thomas, C.E. 1982. Resistance to downy mildew in Cucumis melo plant introductions and American cultivars. Plant Dis. 66:500-502.

Thomas, C.E. 1986. Downy and powdery mildew resistant muskmelon breeding line MR-1. HortScience 21:329.

Thomas, C.E., Y. Cohen, E.L. Jourdain, and H. Eyal. 1987a. Use of reaction types to identify downy mildew resistance in muskmelons. HortScience 22:638-640.

Thomas, C.E., T. Inaba, and Y. Cohen. 1987b. Physiological specialization in Pseudoperonosporacubensis. Phytopathology $77: 1621-1624$.

Thomas, C.E. and E.L. Jourdain. 1992. Evaluation of melon germplasm for resistance to downy mildew. HortScience 27:434-436.

Whitaker, T.W. and G.N. Davis. 1962. Cucurbits: Botany, cultivation, and utilization. Interscience, New York.

Williams, P.H. 1985. Crucifer Genetics Cooperative Resource Book. Univ. of Wisconsin, Madison. Section D, p. 3. 